\title{
Demersal Fishing in Areas Beyond National Jurisdiction: A Comparative Analysis of Regional Fisheries Management Organisations
}

\author{
James B. Bell1*, Elena Guijarro-Garcia² and Andrew Kenny ${ }^{1}$ \\ ${ }^{1}$ Centre for Environment, Fisheries and Aquaculture Science, Lowestoft, United Kingdom, ${ }^{2}$ Instituto Español \\ de Oceanografía, CO de Murcia, Murcia, España
}

OPEN ACCESS

Edited by:

Christopher Kim Pham, University of the Azores, Portugal

Reviewed by:

Michael Vecchione National Oceanic and Atmospheric Administration (NOAA), United States

Jeff A. Ardron,

The University of Southampton, United Kingdom

${ }^{*}$ Correspondence: James B. Bell

james.bell@cefas.co.uk

Specialty section:

This article was submitted to Deep-Sea Environments and Ecology, a section of the journal

Frontiers in Marine Science

Received: 07 May 2019 Accepted: 05 September 2019

Published: 11 October 2019

Citation:

Bell JB, Guijarro-Garcia E and

Kenny A (2019) Demersal Fishing in Areas Beyond National Jurisdiction:

A Comparative Analysis of Regional

Fisheries Management Organisations.

Front. Mar. Sci. 6:596.

doi: 10.3389/fmars.2019.00596
In areas beyond national jurisdiction, there are ten regional fisheries bodies (RFBs) responsible for the management of bottom fisheries (ABNJ). Eight of these organizations are further termed "Regional Fisheries Management Organisations" (RFMOs) and have a legal mandate to regulate the sustainable use of marine living resources on the high seas. The remaining two, both in the equatorial Atlantic, are limited to advisory roles. Here we present comparisons between these organizations' management of deep-water demersal fisheries, with particular respect to how they have respectively, adopted the suite of available measures for the mitigation of significant adverse impacts (SAls) upon vulnerable marine ecosystems (VMEs). Each organization was scored against 99 performance criteria that either related to their capacity to implement management measures ("Capacity"); the number and effectiveness of measures they have implemented ("Action"); and the intensity and spatial extent of the activities they regulate ("Need"). For most organizations, action and need scores were proportional, as the more actions an organization takes to reduce risk to VMEs, the more it reduces the scope for improvement. However, comparisons between capacity and action scores indicate that, in some organizations, there remain several aspects of VME impact mitigation that could be improved. In the case of RFBs, or recently established RFMOs, capacity gaps are still considerable, suggesting that these organizations receive additional scientific, technical, legal, and financial support, to ensure that they are able to meet current and future objectives. Further, there is little evidence of significant cooperation between adjacent or overlapping organizations in the development and application of conservation measures, highlighting the need for an agreement on the management of biodiversity, rather than sectors, in ABNJ.

\footnotetext{
Keywords: deep-sea, areas beyond national jurisdiction, impacts, fisheries, VME
}

Abbreviations: ABNJ, areas beyond national jurisdiction; BBNJ, biodiversity beyond national jurisdiction; CAN, capacity action - need (scoring method in comparative analysis); CCAMLR, Convention For The Conservation Of Antarctic Marine Living Resources; CECAF, Fisheries Committee For The Eastern Central Atlantic; FAO, food and agriculture organization, un; GFCM, General Fisheries Commission for the Mediterranean; GFW, Global Fishing Watch; NAFO, North West Atlantic Fisheries Organisation; NEAFC, Northeast Atlantic Fisheries Commission; NPFC, North Pacific Fisheries Commission; RFB, regional fishery body; RFMO, Regional Fisheries Management Organisation; SAI, significant adverse impact; SDM, species distribution model; SEAFO, South East Atlantic Fisheries Organisation; SIOFA, South Indian Ocean Fisheries Agreement; SPRFMO, South Pacific Regional Fisheries Management Organisation; UNGA, United Nations General Assembly; VME, Vulnerable Marine Ecosystem (variously defined); VMS, vessel monitoring system; WECAFC, Western Central Atlantic Fishery Commission; WG, working group. 


\section{INTRODUCTION}

Fishing activities in the majority of the world's oceans are subject to oversight by relatively few organizations. In ABNJ, the organization responsible for management of living resources harvested by fishing is determined by whether or not the species are considered highly migratory, under Annex II of the UN Convention on the Law of the Sea. Highly migratory species are managed by organizations so-called "Tuna-RFMOs," but for demersal species or those with more restricted ranges, there are ten organizations worldwide whose areas of competence cover some $55.6 \%$ of the global ocean, including ABNJ and territorial waters (Table 1 and Figure 1). Of these ten, seven have a legal mandate to enact binding measures in $\mathrm{ABNJ}$ and cover around $76.0 \%$ of the high seas.

The deep-sea plays host to a wide range of habitat types that are commonly, but not exclusively, characterized by low productivity. Many of the species, both those of commercial value or otherwise, that inhabit the deep-sea, display life history traits adapted to slow-growth and high longevity/late maturation (Cailliet et al., 2001), which markedly increases their vulnerability to direct exploitation or other disturbances. Owing to these vulnerabilities, deep-sea fisheries have often been characterized by short periods of high-intensity fishing that can quickly reduce fish stocks below economic levels. Deep-sea fisheries use a range of fixed and mobile gear types and are focused in depths of between 200 and $2000 \mathrm{~m}$, targeting areas of continental slope, seamounts and mid-ocean ridges, both within exclusive economic zones and ABNJ. Since 1950, the mean depth of fishing activity has increased by $350 \mathrm{~m}$ (Mengerink et al., 2014). In this review, we consider how each organization has managed impacts that can arise from deep-water fisheries (deeper than $400 \mathrm{~m}$; Mangi et al., 2016).

The FAO International guidelines for the management of deep-sea fisheries in the High Seas (FAO, 2009) are intended for use by states and RFMOs in formulating and implementing appropriate measures. However, these guidelines have been adopted only by a few coastal and flag states (Rogers and Gianni, 2010). International concern over the impacts of deepsea fishing has been the subject of extensive debate by the UNGA, leading to the adoption of several resolutions to protect deep-sea ecosystems (UNGA resolutions 59/25; 61/105; 64/72), which have been variously adopted by each of the RFMOs (UN Secretary General, 2006; Rogers and Gianni, 2010). RFMOs are mandated to conduct assessments, as to whether significant adverse impacts (SAIs) have occurred upon VME and if stocks are exploited sustainably, and implement measures, according to the precautionary approach as necessary, to mitigate these risks (Rogers and Gianni, 2010; Gianni et al., 2016).

Both fixed and mobile fishing gears can come into contact with the sea floor during fishing operations, and consequently pose a risk of SAIs to benthic fauna, particularly those associated with vulnerable marine ecosystems (VME), which are the focus of this review. VMEs are those which host assemblages with one or more of the following attributes: relatively high proportions of rare species; important contribution to key ecosystem functions; structural fragility; and life history traits such as slow growth rates, late maturity or low/unpredictable recruitment (Kenchington et al., 2014). Such ecosystems, whilst not usually the target of commercial activity themselves, are considered to be an important source of habitat for commercial species and thus contribute toward the long-term viability of a stock (Pham et al., 2015). The scale and significance of an impact determines whether it can be considered a SAI (Martin-Smith, 2009; Kenchington et al., 2014). SAIs are negative, long-term consequences for ecosystem function and natural productivity, and the relatively low resilience of deep-sea ecosystems highlights the importance of protecting seabed habitats as an integral part of deep-sea fisheries management (Mangi et al., 2016; Kenny et al., 2018; Koen-Alonso et al., 2019). Assessments of SAIs however, do not always meet FAO criteria and fishing activities that create SAIs are still permitted over large areas of sensitive habitats (Gianni et al., 2016).

Conceptually, the application of fisheries management may be thought of as a trade-off between the "cost" of management activities (data acquisition and stock assessments, closure of fishing grounds etc.) versus the amount of expected "reward" (i.e., fisheries product) (Figure 2). This schema allows for the contextualization of the precautionary principle within fisheries economics, to aid in the prioritization of particular areas where increased management focus is most needed. For example, in low-effort fisheries with relatively few ecosystem impacts (e.g., the deep-sea red crab pot fishery in SEAFO Division B1), the need for explicit oversight is less warranted, and indeed less economic, than for more intensive fisheries with greater potential for impacts (e.g., demersal trawling in the NAFO regulatory area).

Some RFMOs have been proactive in formulating rules related to deep-sea fisheries exploitation but ambition and resultant implementation of these measures is uneven. While RFMOs are given a central place in the management of these fisheries, they can vary widely in scope, authority, participation by fishing nations, and the robustness of the scientific advice provided (Cullis-Suzuki and Pauly, 2010; Clark et al., 2015; Wright et al., 2015; Gianni et al., 2016). Consequently, the different scientific approaches in RFMOs for deep-sea fisheries can be quite broad when addressing issues such as: SAI thresholds, fishing footprint and fishing intensity calculation, application of models of VME indicator species occurrence, method for defining risk of impacts, scale and significance of the impact of fishing on VMEs, and encounter protocols. The most common avoidance or mitigation measures are area closures, gear limitations, encounter rules, and stricter controls upon exploratory fishing (Penney et al., 2009; Aguilar et al., 2017). There remain concerns that low observer coverage levels, inadequate measures, and poor compliance limits the effectiveness of management in these areas, particularly for the application of encounter rules (Rogers and Gianni, 2010; Auster et al., 2011; Gianni et al., 2016).

We reviewed ten organizations (Table 1) with the remit to advise upon and/or regulate deep-sea fishing against a set of criteria to evaluate their relative performance, with particular focus on the ways in which they mitigate impacts upon VMEs. 
TABLE 1 | Organizations reviewed in this article. RFMO waters, except GFCM, are only in ABNJ. RFB waters include territorial seas (Figure 1).

\begin{tabular}{|c|c|c|c|}
\hline Name & Legal status & General area of jurisdiction & Key fish stocks \\
\hline $\begin{array}{l}\text { Convention for the Conservation of Antarctic } \\
\text { Marine Living Resources (CCAMLR) }\end{array}$ & RFMO* & $\begin{array}{l}\text { Southern Ocean, south of sub-polar } \\
\text { Front. }\end{array}$ & $\begin{array}{l}\text { Patagonian and Antarctic Toothfish, Krill, and } \\
\text { Mackerel Icefish. }\end{array}$ \\
\hline $\begin{array}{l}\text { Fisheries Committee for the Eastern Central } \\
\text { Atlantic (CECAF) }\end{array}$ & RFB & $\begin{array}{l}\text { Sub-tropical and tropical Atlantic, east } \\
\text { of } 40^{\circ} \mathrm{W} \text {. }\end{array}$ & $\begin{array}{l}\text { Multiple pelagic and demersal finfish and } \\
\text { crustacean stocks. }\end{array}$ \\
\hline $\begin{array}{l}\text { General Fisheries Commission for the } \\
\text { Mediterranean (GFCM) }\end{array}$ & RFMO & Mediterranean and Black Seas. & $\begin{array}{l}\text { Multiple pelagic and demersal finfish and } \\
\text { crustacean stocks. }\end{array}$ \\
\hline $\begin{array}{l}\text { Northwest Atlantic Fisheries Organization } \\
\text { (NAFO) }\end{array}$ & RFMO & Northwest Atlantic, west of $42^{\circ} \mathrm{W}$. & $\begin{array}{l}\text { Temperate groundfishes (e.g. cod, redfish) and } \\
\text { cephalopods. }\end{array}$ \\
\hline $\begin{array}{l}\text { North-east Atlantic Fisheries Commission } \\
\text { (NEAFC) }\end{array}$ & RFMO & $\begin{array}{l}\text { Northeast Atlantic and Arctic Oceans, } \\
42^{\circ} \mathrm{W}-50^{\circ} \mathrm{E} \text {. }\end{array}$ & $\begin{array}{l}\text { Temperate groundfishes (e.g. redfish, whiting) } \\
\text { and sharks. }\end{array}$ \\
\hline North Pacific Fisheries Commission (NPFC) & RFMO & North Pacific, north of $10^{\circ} \mathrm{N}$. & $\begin{array}{l}\text { Demersal fishes (e.g. alfonsino), and pelagic } \\
\text { finfish and cephalopods. }\end{array}$ \\
\hline $\begin{array}{l}\text { South East Atlantic Fisheries Organisation } \\
\text { (SEAFO) }\end{array}$ & RFMO & South-east Atlantic, east of $20^{\circ} \mathrm{W}$. & $\begin{array}{l}\text { Geryonid crabs Patagonian Toothfish Orange } \\
\text { Roughy }\end{array}$ \\
\hline $\begin{array}{l}\text { South Indian Ocean Fisheries Agreement } \\
\text { (SIOFA) }\end{array}$ & RFMO & South Indian Ocean, south of $10^{\circ} \mathrm{S}$ & $\begin{array}{l}\text { Alfonsino, Pelagic armourhead, geryonid crabs, } \\
\text { Patagonian Toothfish. }\end{array}$ \\
\hline $\begin{array}{l}\text { South Pacific Regional Fisheries Management } \\
\text { Organisation (SPRFMO) }\end{array}$ & RFMO & South Pacific, south of $0^{\circ} \mathrm{N}$ & $\begin{array}{l}\text { Multiple pelagic and demersal finfish and } \\
\text { cephalopod stocks. }\end{array}$ \\
\hline $\begin{array}{l}\text { Western Central Atlantic Fishery Commission } \\
\text { (WECAFC) }\end{array}$ & $\mathrm{RFB}^{* *}$ & $\begin{array}{l}\text { Western sub-tropical and tropical } \\
\text { Atlantic and Caribbean, west of } 40^{\circ} \mathrm{W}\end{array}$ & $\begin{array}{l}\text { Spiny Lobster, small pelagic finfishes and } \\
\text { miscellaneous demersal fisheso }\end{array}$ \\
\hline
\end{tabular}

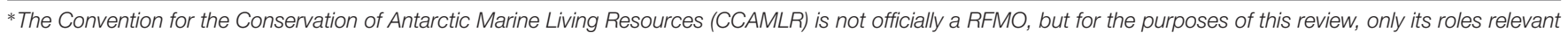
to the management of demersal fisheries are considered. **Legal status under review, with aspiration to become a RFMO. aAs defined by FAO.

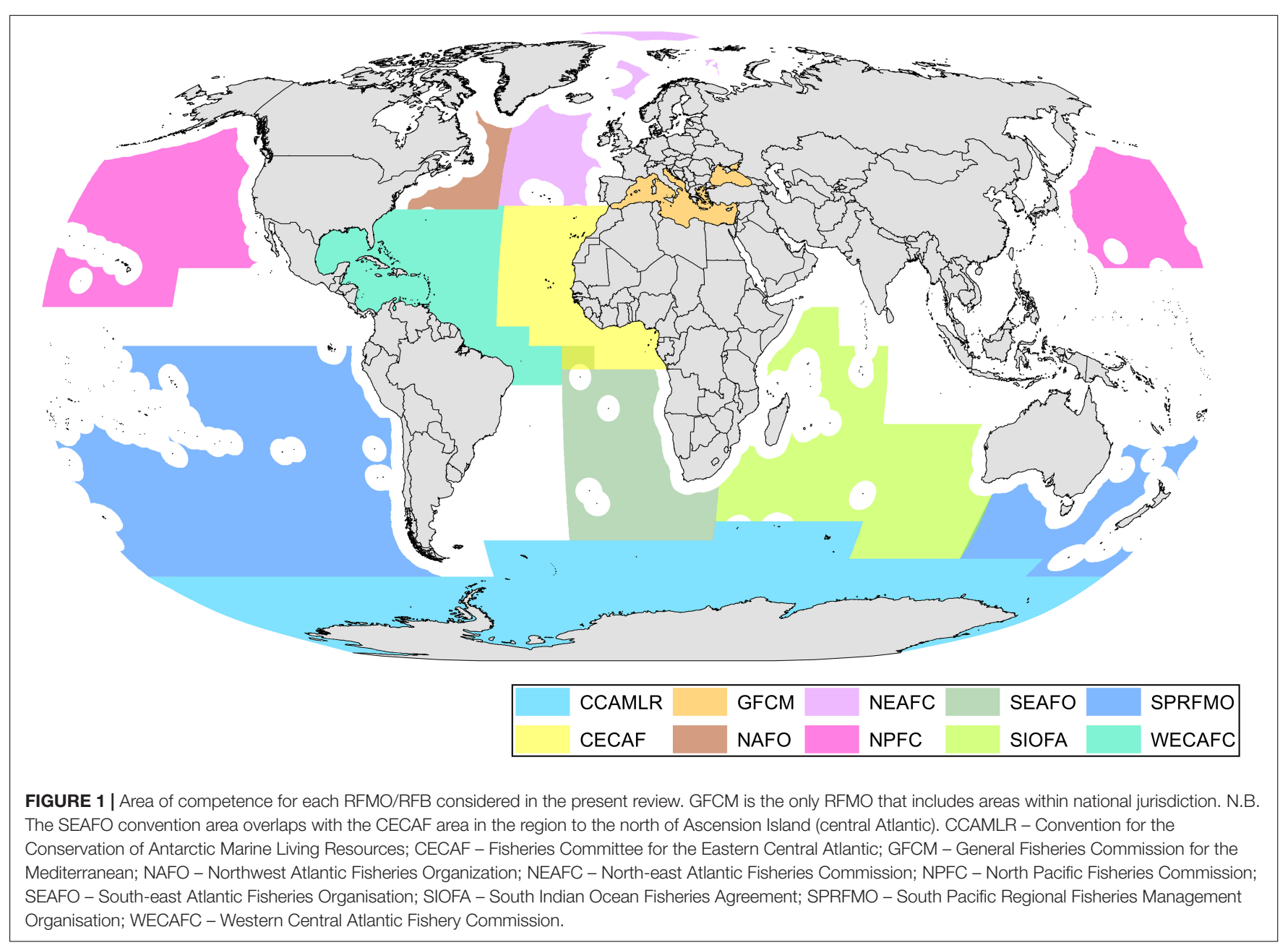




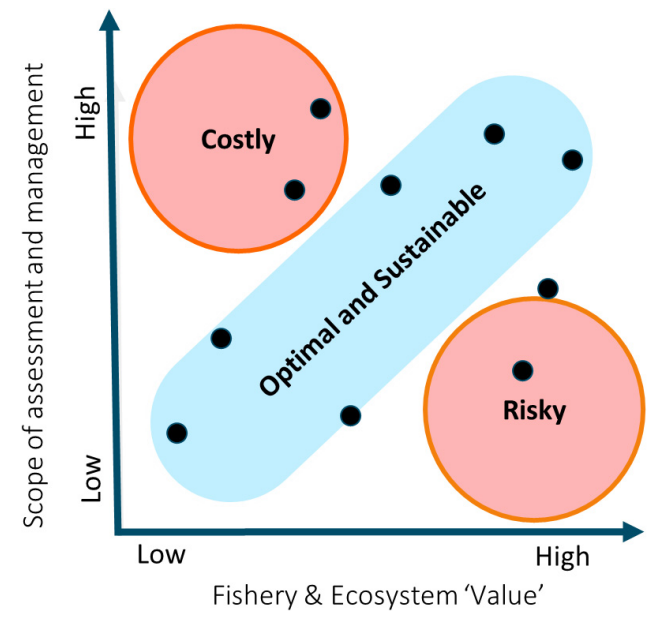

FIGURE 2 | Conceptual risk-reward framework for fisheries management.

\section{MATERIALS AND METHODS}

Each organization was scored against 99 specific criteria in MayJune 2018, using information that was publicly available through their respective websites and published reports and relevant to some aspect of their organizational structure, the activities they manage, or ecological characteristics of their areas of competence. The criteria were developed with the authors of the original report (Bell et al., 2019) and staff at the European Maritime and Fisheries Fund (EMFF) with the aim of covering as many characteristics of each organization as possible (Supplementary Appendix S1, S4). Secretariats were not contacted to request information as part of the effort to minimize bias.

The criteria were scored using a mix of quantitative (e.g., area size of the organization's regulatory area/area of competence, or the proportion of fishing trips that are subject to independent observation) and qualitative (e.g., whether the organization has agreed a definition of VME) sources of information. Qualitative information was scored against pre-agreed criteria and all scores for a given organization were reviewed by an author not involved in the primary data collection. The criteria covered a broad range of topics, including organizational structure (e.g., annual budget of the organization); collection and use of fisheries-dependent and research data; potential sources of SAIs; and management measures adopted by the organization.

Scores from 46 of the 99 criteria were disregarded from subsequent analyses for one or more of the following reasons:

(1) A direct comparison was not considered meaningful. For instance, typical stock assessment interval varied between and within organizations, tending to be more regular in organizations with a longer history, and a higher proportion of developed Contracting Parties (, e.g., NEAFC or NAFO). However, this difference does not effectively comment on whether the stock assessment interval is adequate, so it would not be valid to assume that a shorter interval constituted "better" management;
(2) There were insufficient organizations for which data could be gathered (seven or fewer), or all organizations were scored at zero;

(3) Concerns about bias or incomparability in scores could not be resolved, particularly where concerns over differences in the quality of information reported by the organizations were raised (e.g., fishing effort was not equivalently reported by each organization).

Each of the remaining 53 criteria were classified according to whether they best represented either: organizational capacity (i.e., what the organization has the authority and resources to deliver); management actions (i.e., measures that the organization has previously implemented); or management need (i.e., the level of management measures that are still required) (Supplementary Appendix S1). These scores are collectively referred to as CAN scores and are analogous to the $\mathrm{P}$ and $\mathrm{Q}$ (theoretical performance, i.e., capacity, and actual performance, i.e., action, respectively) scoring method used by Cullis-Suzuki and Pauly (2010) but take an additional step of contextualizing capacity and action scores within potential threat levels (i.e., need), such as fishing intensity. Need scores also included an element of penalization (e.g., organizations scored higher in need if certain actions, such as mandated observer coverage levels, had not, or could not have been implemented; Supplementary Appendix S1).

Scores were also classified as relating to "fishery-ecosystem value" (Figure 2), a subset of scores categorized as need that excluded criteria such as whether the organization permitted the use of towed bottom-contacting gears (a management decision not related to the inherent biodiversity "value" of the area). First sale value of the fisheries could not be determined and so these scores are derived from the inference that a larger fleet, and/or higher fishing effort begets a higher "value." The ecosystem value of non-target species was indicated by scores in criteria such as the extent and diversity of the VME species and habitats present.

All scores were normalized to the maximum value within each criterion, to avoid bias/incomparability arising from the differing scales between criteria. Untransformed CAN scores were used to calculate a Euclidean dissimilarity matrix and visualized with non-metric multidimensional scaling and average linkage hierarchical clustering using the "Vegan" package in R (Oksanen et al., 2019). The mean and standard deviation within each classification was also calculated to compare each organizations' overall position and Spearman's rank correlation test applied. Relationship between scores was visualized using generalized linear models with 95\% confidence intervals.

\section{Limitations and Caveats}

Since each criterion's scores were normalized (so that the highest value $=1$ ), the results presented here should be considered relative measures only; high or low scores should not necessarily be interpreted as an organization having adopted best practice or failing to meet its objectives. The study combined criteria with categorical and quantitative scores and as such, individual criteria often had non-normal error distributions (especially for binary scores; Supplementary Appendix S1). Mean scores (and standard deviation) were sensitive to binary scores, but 
the majority of scores were objective, comparable measures (e.g., fishing effort) that largely limited the potential for this error in interpretation. Scoring methods were quantitative in as many cases as possible but some were necessarily qualitative, in which case scoring methods were standardized (Supplementary Appendix S1). Despite this, and the wide range of criteria used, differences in information accessibility between organizations, or between individual author's perceptions, likely still contributed some residual source of error.

Organizations were not scored for measures that were still under consideration at the time of data collection, though we note that some improvements were being considered at the time of writing (e.g., proposal of new fishery closed areas in SIOFA and GFCM). In some cases, comparable data were very difficult to acquire via publicly accessible sources of information and so, where possible, supplementary spatial data were also acquired, such as daily fishing effort data from the GFW portal (Kroodsma et al., 2018), and global bathymetric data (Ryan et al., 2009). GFW data were gridded at $0.01^{\circ}$ resolution, and the mean number of fishing hours per cell between 2012 and 2016 was taken as an estimate of fishing intensity within each of the organizations' areas of competence. The use of GFW data means that such results are biased toward vessels that are large enough to be expected to use a position beacon, and compliant enough to ensure that the beacon is operational, but comparable estimates of fishing effort within each RFMO were otherwise impossible to constrain.

\section{RESULTS}

\section{Typical Management Measures}

All the organizations (that have had opportunity to do so), have implemented some combination of the following precautionary or reactive measures to limit or avoid the risk of SAI upon VMEs:

(1) Fishery closed areas;

(2) Fishing areas closed to specific gears;

(3) Exploratory fishing rules, whereby fishing in new areas is subject to increased scrutiny; and

(4) Encounter rules, through which vessels are expected to report instances of VME species bycatch exceeding a given threshold and cease fishing within a stated distance of the last fishing event.

However, the extent to which each of these measures has been adopted, varied widely between organizations. For example, the proportion of area closed to some or all kinds of fishing gears ranged between $0 \%$ in SIOFA and SPRFMO, to $77.4 \%$ in GFCM (though the vast majority of this area is deeper than $1000 \mathrm{~m}$ and closed to bottom trawling only). Where implemented, the proportion of fishing closed areas ranged between 3 and $11 \%$ of the total regulatory area, compared with a fishing footprint extent of between $<1$ and $37 \%$.

\section{Organization Scores}

The capacity and action scores for each organization were broadly proportional to their need $(p=0.11$ and 0.04 respectively, Figures 3A,B). Some organizations however, fell substantially above or below the trend, indicating where there are improvements to be made, or where management has been more precautionary. CECAF scored highest in need, and lowest in capacity and action, although capacity and action scores were comparable to WECAFC. NEAFC, NAFO, and CCAMLR were consistently the highest scoring organizations for capacity and action, with commensurately low scores in need (Figures 3A,B).

Comparisons between capacity and action (i.e., what an organization could have done, versus what it actually has done) highlight some interesting cases where an organization appears to be performing above or below the "expected relationship." SEAFO and GFCM were the most markedly different from the overall trend (Figure 3C), with SEAFO having a relatively high "action" score given its capacity, whereas for GFCM the opposite appears to be the case.

\section{Multivariate Analyses}

The strongest organizational associations were between CECAF and WECAFC, and NAFO and NEAFC. The dissimilarity between CECAF and WECAFC, and the other organizations was mainly driven by their legal status, and other differences that arise from this (e.g., they could not implement closed areas). Organizations whose convention areas are geographically close also appeared to have some degree of association (e.g., NPFC and SPRFMO, or SEAFO and CCAMLR), especially between NEAFC and NAFO. GFCM was the most distinct, with no clear association with any other organization (Figure 5).

There were a number of categories that were strongly covariate (Figure 5). For instance, if an organization had defined a fishing footprint, it would also have been more likely to have adopted exploratory fishing rules and to require vessels to report position data. Similarly, observer data collection tended to be implemented across the full suite of information sources, and there were no organizations which only mandated collection of target species data.

\section{DISCUSSION}

\section{CAN Scores}

Most organizations had proportionate scores in terms of their actions and fishery-ecosystem value and NEAFC, NAFO and CCAMLR were consistently evident as having done the most to address their management needs, expanding upon previous findings regarding CCAMLR (Gianni et al., 2016). For CECAF and WECAFC, differences largely relate to their legal status but for GFCM, which also scored poorly in terms of its relationship between capacity and action, this likely owing to its area of competence being largely contained within waters under the control of coastal states and thus heavily limiting its ability to make unilateral decisions. Most of the organizations reviewed had need and action scores that were proportional (Figures 3, 4). One of the major drivers of an organization's need score related to the amount of fishing effort. CECAF had the highest need score, driven principally by the relatively high fishing effort in its area of competence (which includes territorial seas), particularly along the west African margin and was amongst the least able to address 

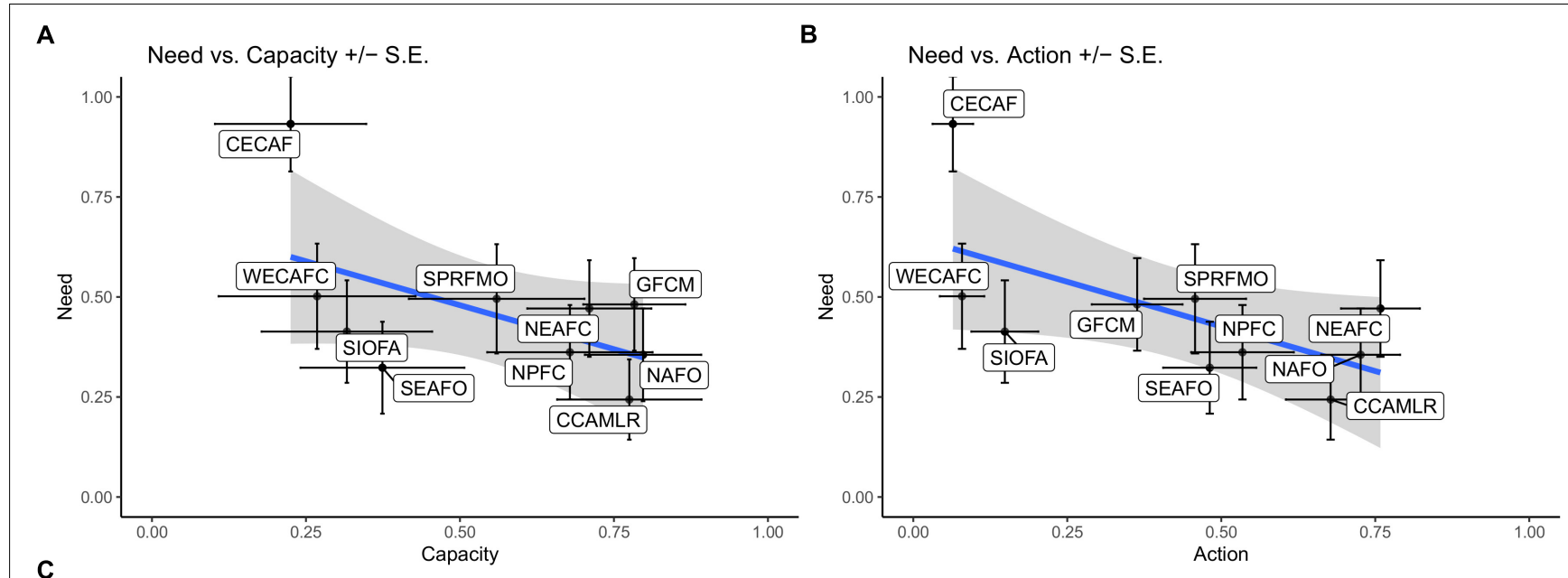

C

Action vs. Capacity +/- S.E.

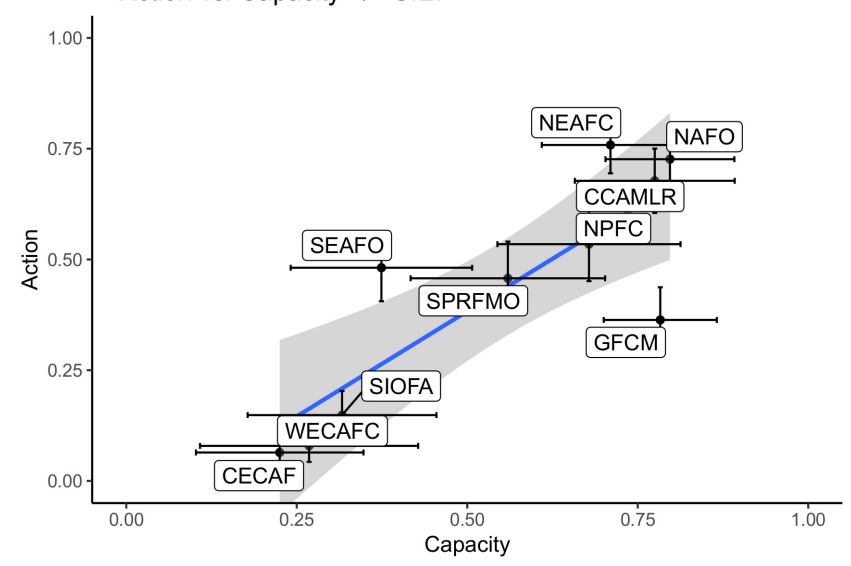

FIGURE 3 | Comparisons of the "capacity," "need" and "action" scores. Gray area = S.E. of generalized linear model (blue line). See Supplementary Appendix S2 for 3-D CAN scores graphic. CCAMLR - Convention for the Conservation of Antarctic Marine Living Resources; CECAF - Fisheries Committee for the Eastern Central Atlantic; GFCM - General Fisheries Commission for the Mediterranean; NAFO - Northwest Atlantic Fisheries Organization; NEAFC - North-east Atlantic Fisheries Commission; NPFC - North Pacific Fisheries Commission; SEAFO - South-east Atlantic Fisheries Organisation; SIOFA - South Indian Ocean Fisheries Agreement; SPRFMO - South Pacific Regional Fisheries Management Organisation; WECAFC - Western Central Atlantic Fishery Commission.

this need, being comprised principally of lesser developed CPs and lacking a convention text. Furthermore, the coastal states bordering the CECAF region are among the least developed and there remain a considerable number of small-scale, artisanal fisheries, whose effort was not captured here but nonetheless contribute much of the fishing effort. WECAFC, although having a similar situation to CECAF in terms of capacity, had far fewer vessels and a much smaller "fishable" area for deep-water fishing (depths between 400 and $2000 \mathrm{~m}$ ).

One of the most useful comparisons, in terms of assessing RFMO performance, was between capacity and action. Of particular interest were SEAFO and GFCM, the organizations that differed most strongly from the mean relationship (Figure 3C). SEAFO's scores indicate that it was relatively cautious in developing mitigation measures, given its capacity, and thus outperforming other organizations in its application of the precautionary approach. However, it has been contended by some that SEAFO's conservation measures (particularly with reference to closed and exploratory areas) are overly detrimental to the opportunities for responsible, low impact fisheries (SEAFO, personal communication). For comparison, the amount of fishing effort expended in SEAFO (mean fishing hours per $0.01^{\circ 2}$ between 2012 and 2016) is around a third of that in SIOFA or SPRFMO, and considerably less than a tenth of that of NAFO or NEAFC.

\section{Effectiveness of Management Measures}

There are several factors affecting the success of measures for the avoidance of SAIs, of which compliance is arguably the most consistent and thus, measures that are easier to enforce tend to have a higher chance of success. Encounter rules are particularly problematic, the main issues being that; (a) encounter rules are reactive and so cannot wholly exclude the risk of SAIs and (b) they rely on vessels reporting instances of VME bycatch, which is often unreliable even in the presence of independent observers (Auster et al., 2011).

In terms of mitigating potential impacts to VME, closed areas are the most effective method but come with the cost of reducing 


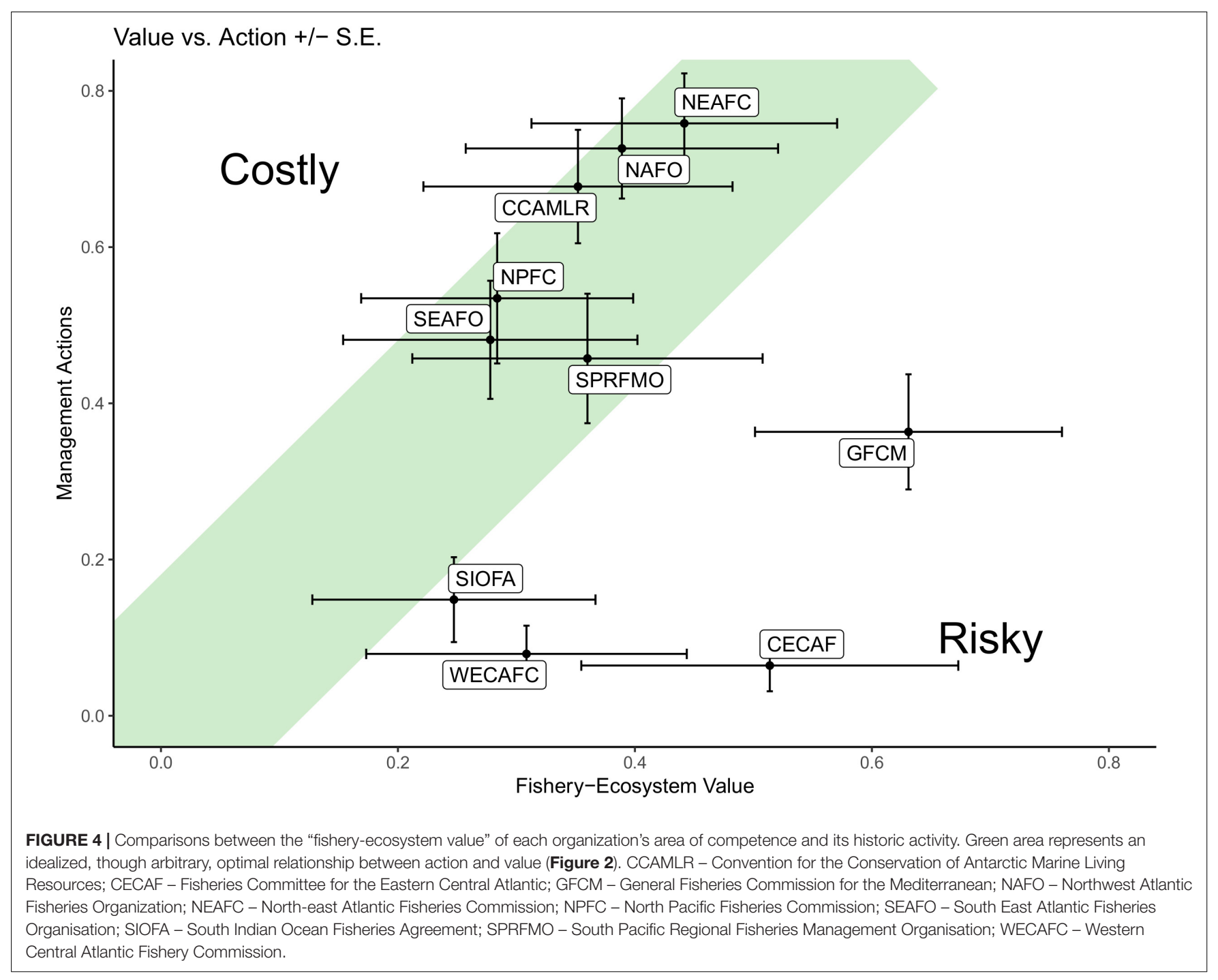

the size of the fishable area. For isolated stocks, this effectively "costs" fishery production and increases the risk of localized serial depletion elsewhere. In such cases, it may be more effective, at least in terms of balancing risk to the stock status of commercial species, to close fishing areas to specific gear types only, since the risk of SAIs is very strongly related to gear type.

There were clear differences between some groups of organizations (Figure 5) that tended to arise from implementation, or lack thereof, of particular measures (Table 2). For instance, organizations that had defined a fishing footprint, usually had also usually taken further actions, such as developing habitat suitability models for VME and establishing closures. This results in a list of relatively few criteria that may be considered to constitute a kind of a "success profile" for demersal fisheries management (Table 2).

\section{Extrinsic Factors}

Among the factors that were not formally captured in the analyses, one that apparently had considerable influence were the number of developed nations, as a proportion of the total membership. This theme was not captured during the review of each organization because it is largely outside of their control (e.g., NAFO, by dint of its coastal and fishing states, intrinsically has a higher proportion of developed member states than SIOFA). The history of the organization also plays an important role in some of the scores expressed here. For instance, although SIOFA has a convention text and so the means to enact measures such closed areas or mandated observer coverage levels, the scientific committee convened for the first time in 2016. This places a serious limit on the amount of progress that it could have made and, whilst a list of candidate VME closures existed in 2018 (SIOFA Scientific Committee, 2018), the Commission had not had the chance to decide whether or not to implement them. These considerations underline the amount of potential increased activity for older, better provisioned organizations, like CCAMLR or NEAFC, versus those such as CECAF or SIOFA.

We also note that WECAFC is considering its position, with a view toward establishing itself as a RFMO. It is therefore worth considering that the analyses presented here are a snapshot of each organization's policies and plans in 


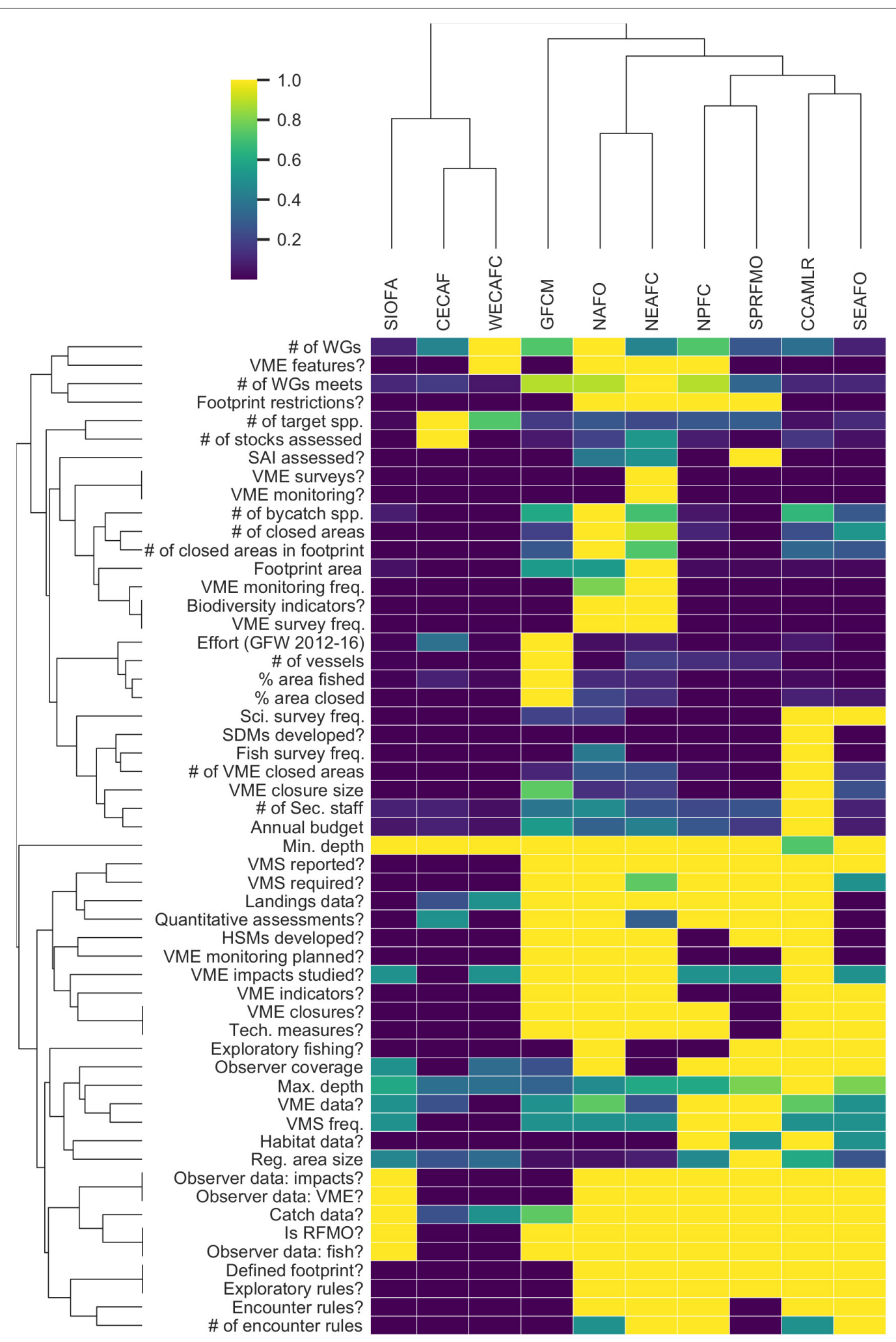

FIGURE 5 | Interactions between RFMOs and different category scores. Average linkage cluster dendrograms (based on Euclidean distance dissimilarity matrix) used to order the plot axes, with color indicating the score value. spp., species; HSM, habitat suitability model; SDM, species distribution model; VMS, vessel monitoring system. N.B. Criteria with too few scores, or where all organizations scored zero, are not included. See Supplementary Appendix S3 for PCA ordination. CCAMLR - Convention for the Conservation of Antarctic Marine Living Resources; CECAF - Fisheries Committee for the Eastern Central Atlantic; 
FIGURE 5 | Continued

GFCM - General Fisheries Commission for the Mediterranean; NAFO - North-west Atlantic Fisheries Organization; NEAFC - North-east Atlantic Fisheries

Commission; NPFC - North Pacific Fisheries Commission; SEAFO - South-east Atlantic Fisheries Organisation; SIOFA - South Indian Ocean Fisheries Agreement;

SPRFMO - South Pacific Regional Fisheries Management Organisation; WECAFC - Western Central Atlantic Fishery Commission.

mid-2018, and that if this analysis were to be repeated, some change would certainly be observable, particularly for those organizations with a relatively short history. Organizations like NAFO or NEAFC are, by comparison, much more well established and, whilst their measures continue to be reviewed, are unlikely to exhibit as much change. This consideration also underlines the need for stakeholders to focus their support upon those organizations that have the least technical, legal or financial capacity.

Particularly in the case of RFBs, the proportion of contracting parties that are developed nations is considerable relevance to an organization's performance. This stems from the legal mechanism whereby vessels flagged to a particular state are bound to its laws, as well as those of the organization in whose area it will fish. In the case of CECAF, the only mandated observer coverage is that of EU-flagged vessels, highlighting the potential for other national or multilateral agreements to assist in improving global fisheries management. In organizations like NAFO or NEAFC, this flag state influence is more prominent in terms of the amount of resource available to conduct scientific research and, for the purposes of this review, particularly that which relates to VMEs and the avoidance/mitigation of SAIs (e.g., habitat suitability modeling).

A complicating factor that emerged during this analysis was the extent to which the history and geopolitical context of each

TABLE 2 | Common characteristics of high and low-moderate scored organizations.

\section{Relatively high scoring organizations NEAFC, NAFO, CCAMLR, SEAFO Relatively low-moderate scoring organizations* CECAF, SIOFA, WECAFC}

High standards of data collection for target fish stocks.

The organization has only recently been established or does not have RFMO status.

Vessel position data used. Low numbers of permanent staff in the secretariat.

VME species/habitats identified, and habitat suitability models developed. Fishing footprint defined and fishery closed areas implemented, both within and outside of fishing footprint.

Studies of SAls have been conducted Lack of fishery independent surveys. and monitoring plans are implemented.

*In addition to scoring low in criteria symptomatic of higher scoring organizations. CCAMLR - Convention for the Conservation of Antarctic Marine Living Resources; CECAF - Fisheries Committee for the Eastern Central Atlantic; GFCM - General Fisheries Commission for the Mediterranean; NAFO - North-west Atlantic Fisheries Organization; NEAFC - North-east Atlantic Fisheries Commission; NPFC - North Pacific Fisheries Commission; SEAFO - South-east Atlantic Fisheries Organisation; SIOFA - South Indian Ocean Fisheries Agreement; SPRFMO - South Pacific Regional Fisheries Management Organisation; WECAFC - Western Central Atlantic Fishery Commission. organization affects its current state. Particular organizations of note here were CCAMLR and GFCM. CCAMLR, except in the case of remote, uninhabited island territories such as South Georgia and the South Sandwich Islands or Heard and McDonald Islands, has no coastal states and all of its fisheries are comprized of industrial scale, distant water fleets. This creates a platform for an expected standard of compliance that other organizations have seemingly found difficult to replicate. GFCM by comparison, is responsible for a wide range of fishing activities, much of which occurs within the $12 \mathrm{~nm}$ territorial seas of its member states. Consequently, although GFCM has the same mandate, to ensure the sustainable management of marine living resources, most measures require the agreement of coastal states. This is considered to be a primary reason for the apparently low activity, relative to capacity, in GFCM.

\section{Regional Conservation Goals}

In terms of the success or failure of wider management objectives, there is concern about the lack of a formalized process for agreeing conservation measures between overlapping or adjacent competent organizations. For example, threshold values for encounter rules are more often than not, just inherited from other, more established RFMOs, rather than being bespoke to their particular area of competence. InterRFMO cooperation (e.g., through ensuring that closed area networks are complementary between adjacent organizations) is apparently relatively limited, and likely worse between RFMOs and other competent authorities, such as the International Seabed Authority (Gjerde et al., 2018). Currently, there is no clear resolution in terms of which organization would take primacy in events such as the ISA wishing to license mining activities in areas of the Mid-Atlantic Ridge already designated as fisheries closed areas by NEAFC, and further covered by the mandate of the Oslo-Paris Convention. The lack of a competent organization that is able to mediate or rule upon such conflicts highlights the need for management of ("the BBNJ agreement" - Ardron et al., 2014; Gjerde et al., 2018; Wright et al., 2019), currently under consideration by the UN General Assembly, pursuant to UNGA resolutions 59/25; 66/288; 72/249. Recognizing that "the problems of ocean space are closely interrelated and need to be considered as a whole" (UNCLOS, 1982), and the need for ecosystem approaches to management, places further demand upon fisheries management organizations but, particularly in the cases of CECAF and WECAFC, these demands are often in excess of what a given organization is functionally able to deliver.

Whilst RFMOs have generally been cognizant of each other's activities, there has historically been relatively little imperative to formally cooperate with each other and with other competent authorities, despite the obvious relevance to broader biodiversity agreements (Rice et al., 2014). With regards the ecosystem-based 
management of VMEs, which RFMOs are already mandated to address (e.g., through UNGA 61/105), the main benefits from a BBNJ agreement would be through the development of regional plans and standardized assessment approaches, and for the harmonization of the wide range of third party agreements (van der Burght et al., 2017). Whilst we have reviewed the performance of each organization individually, the lack of regional management plans means that we cannot comment on how the links between adjacent/overlapping organizations are performing in terms of meeting broader conservation goals.

Some RFMOs have formally adopted agreements or memoranda with international organizations whose remit is focused upon specific taxa, rather than a geographic area (e.g., the North Atlantic Salmon Conservation Organization or the Agreement on the Conservation of Albatrosses and Petrels). In certain cases, these agreements oblige the organization to further develop certain conservation measures, over and above the requirements made by the various UNGA fish stock agreements. However, such arrangements are largely piecemeal, at the discretion of individual commissions, and generally lack the kinds of binding measures that could be championed by the proposed BBNJ authority.

\section{CONCLUSION}

The trends and results presented here, whilst limited to relative differences, provide useful comparisons between different regional fishery management organizations, with particular respect to how they have adopted measures to mitigate adverse impacts upon vulnerable ecosystems. Actions between organizations varied widely but so also did their needs. In considering RFMO performance within the context of indicators of management need, we have demonstrated that, most organizations are achieving a similar balance of permitting fishing activities and promoting ecosystem approach considerations.

Younger RFMOs, and RFBs, are naturally those in most need of targeted support, but there is also much room for improvement in cooperation between competent organizations and the development of standardized approaches for assessing and mitigating adverse impacts upon vulnerable marine ecosystems.

Few organizations have assessed levels of fishing intensity that result in SAIs meaning that in most cases, precautionary management still forms the basis of any conservation measures implemented. Precautionary measures however, are not made equal and have varying challenges in their application. Encounter rules for instance are only effective when observer coverage and competence is adequate and when organizations are diligent in reviewing and acting upon encounter reports. In the absence of

\section{REFERENCES}

Aguilar, R., Perry, A. L., and López, J. (2017). "Conservation and management of vulnerable marine benthic ecosystems," in Marine Animal Forests, eds S. Rossi, B. Bramanti, A. Gofi, and C. Orejas (Berlin: Springer). suitable levels of scrutiny, such management may actually not be considered precautionary and underlines the need for bespoke assessment of adverse impacts in each organization.

\section{DATA AVAILABILITY STATEMENT}

All datasets generated for this study are included in the manuscript/Supplementary Files.

\section{AUTHOR CONTRIBUTIONS}

All authors participated in writing and commenting on all aspects of the manuscript. JB prepared the figures.

\section{FUNDING}

This work was supported by EASME, under the European Commission (EC) European Marine and Fisheries Fund (Bell et al., 2019; Framework Contract EASME/EMFF/2016/008), and we gratefully acknowledge the contributions of those involved in the preparation of the original document, upon which the present manuscript is based.

\section{ACKNOWLEDGMENTS}

We thank the associate editor and the two reviewers for their valuable contributions. The funding agency gave formal permission for these results to be published but was not involved in the preparation of the present manuscript. The results of this study are the property of the EC, but any opinions expressed in this manuscript are those of the authors, and do not necessarily represent those of the EC.

\section{SUPPLEMENTARY MATERIAL}

The Supplementary Material for this article can be found online at: https://www.frontiersin.org/articles/10.3389/fmars. 2019.00596/full\#supplementary-material

APPENDIX S1 | List of criteria and their scoring methods and classifications. APPENDIX S2 | 3-D dimension relationship between organizations' CAN scores.

APPENDIX S3 | 3-D relationship between organizations along three most important principal components axes.

APPENDIX S4 | Category scores collated for each organisation.

Ardron, J. A., Clark, M. R., Penney, A. J., Hourigan, T. F., Rowden, A. A., Dunstan, P. K., et al. (2014). A systematic approach towards the identification and protection of vulnerable marine ecosystems. Mar. Policy 49, 146-154. doi: 10.1016/j.marpol.2013.11.017

Auster, P. J., Gjerde, K., Heupel, E., Watling, L., Grehan, A., and Rogers, A. D. (2011). Definition and detection of vulnerable marine ecosystems on the high 
seas: problems with the "move-on" rule. ICES J. Mar. Sci. 68, 254-264. doi: 10.1093/icesjms/fsq074

Bell, J. B., Guijarro-García, E., Abellán, L., Carbonell-Quetglas, A., Clark, J., Durán-Muñoz, P., et al. (2019). Scientific Approaches for the Assessment and Management of Deep-Sea Fisheries and Ecosystems in RFMOs and RFBs. EASME/EMFF/2016/008. Lowestoft: CEFAS, 171.

Cailliet, G. M., Andrews, A. H., Burton, E. J., Watters, D. L., Kline, D. E., and FerryGraham, L. A. (2001). Age determination and validation studies of marine fishes: do deep-dwellers live longer? Exp. Gerontol. 36, 739-764. doi: 10.1016/ s0531-5565(00)00239-4

Clark, N. A., Ardron, J. A., and Pendleton, L. H. (2015). Evaluatng the basic elements of transparency of regional fisheries management organizations. Mar. Policy 57, 158-166. doi: 10.1016/j.marpol.2015.03.003

Cullis-Suzuki, S., and Pauly, D. (2010). Failing the high seas: a global evaluation of regional fisheries management organizations. Mar. Policy 34, 1036-1042. doi: 10.1016/j.marpol.2010.03.002

FAO (2009). International Guidelines for the Management of Deep-sea Fisheries in the High Seas. Rome: FAO, 73.

Gianni, M., Fuller, S., Currie, D. E. J., Schleit, K., Pike, B., Goldsworthy, L., et al. (2016). How Much Longer Will it Take? A ten Year Review of the Implementation of United Nations General Assembly Resolition 61/105, 64/72 and66/68 on the Management of bottom fisheries in Areas Beyondnational Jurisdiction, Vol. 4. Amsterdam: Deep Sea Conservation Coalition.

Gjerde, K., Boteler, B., Durussel, C., Rochette, J., Unger, S., and Wright, G. (2018). Conservation and Sustainable Use of Marine Biodiversity in Areas Beyond National Jurisdiction: Options for Underpinning a Strong Global BBNJ Agreement through Regional and Sectoral Governance. Potsdam: IASS Policy Brief.

Kenchington, E., Murillo, F. J., Lirette, C., Sacau, M., Koen-Alonso, M., Kenny, A. J., et al. (2014). Kernel density surface modelling as a means to identify significant concentrations of vulnerable marine ecosystem indicators. PLoS One 9:e109365. doi: 10.1371/journal.pone.0109365

Kenny, A. J., Cambell, N., Koen-Alonso, M., Pepin, P., and Diz, D. (2018). Delivering sustainable fisheries through adoption of a risk-based framework as part of an ecosystem approach to fisheries management. Mar. Policy 93, 232-240. doi: 10.1016/j.marpol.2017.05.018

Koen-Alonso, M., Pepin, P., Fogarty, M. J., Kenny, A. J., and Kenchington, E. L. R. (2019). The Northwest Atlantic fisheries organisation roadmap for the development and implementation of an ecosystem approach to fisheries: structure, state of development, and challenges. Mar. Policy 100, 342-352. doi: 10.1016/j.marpol.2018.11.025

Kroodsma, D. A., Mayorga, J., Hochberg, T., Miller, N. A., Boerder, K., Ferretti, F., et al. (2018). Tracking the global footprint of fisheries. Science 359, 904-908. doi: 10.1126/science.aao5646

Mangi, S. C., Kenny, A., Readdy, L., Posen, P., Ribeiro-Santos, A., Neat, F. C., et al. (2016). The economic implications of changing regulations for deep sea fishing under the European common fisheries policy: UK case study. Sci. Total Environ. 562, 260-269. doi: 10.1016/j.scitotenv.2016.03.218

Martin-Smith, K. (2009). A risk-management framework for avoiding significant adverse impacts of bottom fishing gear on vulnerable marine ecosystems. CCAMLR Sci. 16, 177-193.

Mengerink, K. J., Van Dover, C. L., Ardron, J., Baker, M., Escobar-Briones, E., Gjerde, K., et al. (2014). A call for deep-ocean stewardship. Science 344, 696-698. doi: 10.1126/science. 1251458

Oksanen, J., Blanchet, F. G., Friendly, M., Kindt, R., Legendre, P., McGlinn, D., et al. (2019). Package Vegan 2.5-4, https://cran.r-project.org/web/packages/ vegan/vegan.pdf (accessed June 1, 2018).

Penney, A. J., Parker, S. J., and Brown, J. H. (2009). Protection measures implemented by New Zealand for vulnerable marine ecosystems in the South Pacific Ocean. Mar. Ecol. Prog. Ser. 397, 341-354. doi: 10.3354/meps08300

Pham, C. K., Vandeperre, F., Menezes, G., Porterio, F., Isidro, E., and Morato, T. (2015). The importance of deep-sea vulnerable marine ecosystems for demersal fish in the Azores. Deep Sea Res. Part I Oceanogr. Res. Papers 96, 80-88. doi: 10.1016/j.dsr.2014.11.004

Rice, J., Lee, J., and Tandstad, M. (2014). “Parallel initiatives: CBD’s ecologically of biologically significant areas (EBSAs) and FAI's vulnerable marine ecosystems
(VMEs) criteria and processes," In Governance of Marine Fisheries and Biodiversity. Interaction and Coevolution, S. M. Garcia., J. Rice, and A. Charlies (Hoboken: Wiley).

Rogers, A. D., and Gianni, M. (2010). The Implementation of UNGA Resolutions 61/105 and 64/72 in the Management of Deep-Sea Fisheries on the High Seas. Amsterdam: Deep Sea Conservation Coalition.

Ryan, W. B. F., Carbotte, S. M., Coplan, J. O., O’Hara, S., Melkonian, A., Arko, R., et al. (2009). Global multi-resolution topography synthesis. Geochem. Geophys. Geosyst. 10, Q03014.

SIOFA Scientific Committee (2018). Report of the Third Meeting of the Scientific Committee of the Southern Indian Ocean Fisheries Agreement (SIOFA). La Réunion: SIOFA

UN General Assembly (2005). Resolution 59/25: Sustainable Fisheries, Including Through the 1995 Agreement for the Implementation of the Provisions of the United Nationals Convention on the Law of the Sea of 10 December 1982 Relating to the Conservation and Management of Straddling Fish Stocks and Highly Migratory Fish stocks, and Related Instruments. New York, NY: UN General Assembly.

UN General Assembly (2007). Resolution 61/105: Sustainable Fisheries, Including Through the 1995 Agreement for the Implementation of the Provisions of the United Nationals Convention on the Law of the Sea of 10 December 1982 relating to the Conservation and Management of Straddling Fish Stocks and Highly Migratory Fish stocks, and Related Instruments. New York, NY: UN General Assembly.

UN General Assembly (2010). Resolution 64/72: Sustainable Fisheries, Including Through the 1995 Agreement for the Implementation of the Provisions of the United Nationals Convention on the Law of the Sea of 10 December 1982 relating to the Conservation and Management of Straddling Fish Stocks and Highly Migratory Fish stocks, and Related Instruments. New York, NY: UN General Assembly.

UN General Assembly (2012). Resolution 66/288: The future we want. New York, NY: UN General Assembly.

UN General Assembly (2017). Resolution 72/249: Intergovernmental Conference on an international legally binding instrument under the United Nations Convention on the Law of the Sea on the conservation and sustainable use of marine biological diversity of areas Beyond National Jurisdiction. New York, NY: UN General Assembly.

UN Secretary General (2006). Impacts of fishing on Vulnerable Marine Ecosystems: Actions Taken by States and Regional fisheries Management Organizations and Arrangements to Give Effect to Paragraphs 66 to 69 of General Assembly Resolution 59/25 on Sustainable Fisheries, Regarding the Impacts of Fishing on Vulnerable Marine Ecosystems. Manhattan, NY: UN Secretary General.

UNCLOS (1982). United Nations Convention on the Law of the Sea. Montego Bay: UNCLOS.

van der Burght, N., Dupont, C., Mastor, R., Potestio, S., Smith, N., and Vancauwenbergh, S. (2017). Research for PECH Committee - Regional Ocean Governance in Europe: The Role of Fisheries. Brussels: European Parliament, Policy Department for Structural and Cohesion Policies, 1-122.

Wright, G., Ardron, J., Gjerde, K., Currie, D., and Rochette, J. (2015). Advancing marine biodiversity protection through regional fisheries management: a review of bottom fisheries closures in areas beyond national jurisdiction. Mar. Policy 61, 134-148. doi: 10.1016/j.marpol.2015.06.030

Wright, G., Gjerde, K., Johnson, D. E., Finkelstein, A., Ferreira, M. A., Dunn, D. C., et al. (2019). Marine spatial planning in areas beyond national jurisdiction. Mar. Policy. 832-839. doi: 10.1016/j.marpol.2018.12.003

Conflict of Interest: The authors declare that the research was conducted in the absence of any commercial or financial relationships that could be construed as a potential conflict of interest.

Copyright (c) 2019 Bell, Guijarro-Garcia and Kenny. This is an open-access article distributed under the terms of the Creative Commons Attribution License (CC BY). The use, distribution or reproduction in other forums is permitted, provided the original author(s) and the copyright owner(s) are credited and that the original publication in this journal is cited, in accordance with accepted academic practice. No use, distribution or reproduction is permitted which does not comply with these terms. 